\title{
Angiolactone, a new Butyrolactone isolated from the terrestrial myxobacterium, Angiococcus sp.
}

\author{
Ritesh Raju, Ronald Garcia and Rolf Müller
}

The Journal of Antibiotics (2014) 67, 725-726; doi:10.1038/ja.2014.55; published online 7 May 2014

\section{DESCRIPTION}

Myxobacteria are recognized as one of the outstanding prokaryotic sources of bioactive compounds in nature. More than 100 core structures with diverse biological activities had been elucidated, most of which were novel. ${ }^{1}$ In the continuous screening program for antiinfectives focusing on novel, rare, and unexplored myxobacterial taxa, great potential was discovered in Angiococcus disciformis SBAn001. The strain was routinely cultivated in TS- 6 medium (Tryptone (Difco, BD Biosciences, San Jose, CA, USA) $0.6 \%, \mathrm{MgSO}_{4} \cdot 7 \mathrm{H}_{2} \mathrm{O} 0.2 \%$, soluble starch (Roth, Karlsruhe, Germany) 0.4\%, HEPES 1.19\%, pH adjusted to 7.2 with $\mathrm{KOH}$ before autoclaving).

Shake flask fermentation was performed in 10 liters volume TS- 6 medium for 10 days at $30{ }^{\circ} \mathrm{C}, 160$ r.p.m., after which on the 3 rd day amberlite resin XAD-16 was added $(2 \% \mathrm{v} / \mathrm{v})$. The resin was filtered from the fermented broth and washed twice with distilled water, followed by extraction with methanol $(500 \mathrm{ml} \times 2)$. The $\mathrm{MeOH}$ extract was then dried in vacuo yielding a crude extract of $126 \mathrm{mg}$ fraction. This was then partitioned between $30 \mathrm{ml}$ of hexane, $\mathrm{CH}_{2} \mathrm{Cl}_{2}$ and $\mathrm{MeOH}$ to afford 33.6, 20.6 and $42.3 \mathrm{mg}$ fractions, respectively. The $\mathrm{MeOH}$ fraction was subsequently purified by semi-preparative reverse-phase HPLC to yield the UV absorbing $\left(\lambda_{\max } 260 \mathrm{~nm}\right)$ compound 1 (Figure $1 ; t_{\mathrm{R}}=24.2 \mathrm{~min} ; 0.3 \mathrm{mg}$ ). A detailed account of the spectroscopic analysis leading to the assignment of angiolactone (1) is presented below.

HRESI ( + )MS analysis of $\mathbf{1}$ (Table 1 ) revealed a pseudomolecular ion $\left([\mathrm{M}+\mathrm{Na}]^{+}\right)$indicative of a molecular formula $\left(\mathrm{C}_{23} \mathrm{H}_{26} \mathrm{O}_{4}\right)$ requiring 11 double bond equivalents. Examination of the NMR (methanol- $d_{4}$ ) data (Table 2, Supplementary Figures S1-S4) revealed $15 \mathrm{sp}^{2}$ carbon resonances, 12 of which were attributed as aromatic $\left(\delta_{\mathrm{C}}\right.$ $115.3-157.4)$, an olefinic double bond $\left(\delta_{\mathrm{C}} 105.8,153.2\right)$ and an ester carbonyl $\left(\delta_{\mathrm{C}} 175.1\right)$ accounting for 7 double bond equivalent and requiring that 1 be tricyclic. Analysis of the $1 \mathrm{D}$ and $2 \mathrm{D}$ NMR data revealed equivalent aromatic protons $\mathrm{H}-2^{\prime \prime}$ plus $\mathrm{H}-6^{\prime \prime}\left(\delta_{\mathrm{H}} 7.00, \mathrm{~d}\right.$, 7.6) and $\mathrm{H}-3^{\prime \prime}$ plus $\mathrm{H}-5^{\prime \prime}\left(\delta_{\mathrm{H}} 6.63, \mathrm{~d}, 8.3\right)$, which showed HMBC correlations to their same HSQC-correlated ${ }^{13} \mathrm{C}$ resonances, the quaternary carbons $\mathrm{C}-1^{\prime \prime}\left(\delta_{\mathrm{C}} 127.5\right), \mathrm{C}-4^{\prime \prime}\left(\delta_{\mathrm{C}} 157.4\right)$ and to the methylene C- $6\left(\delta_{\mathrm{C}} 41.2\right)$, indicating the presence of a 4-hydroxybenzyl

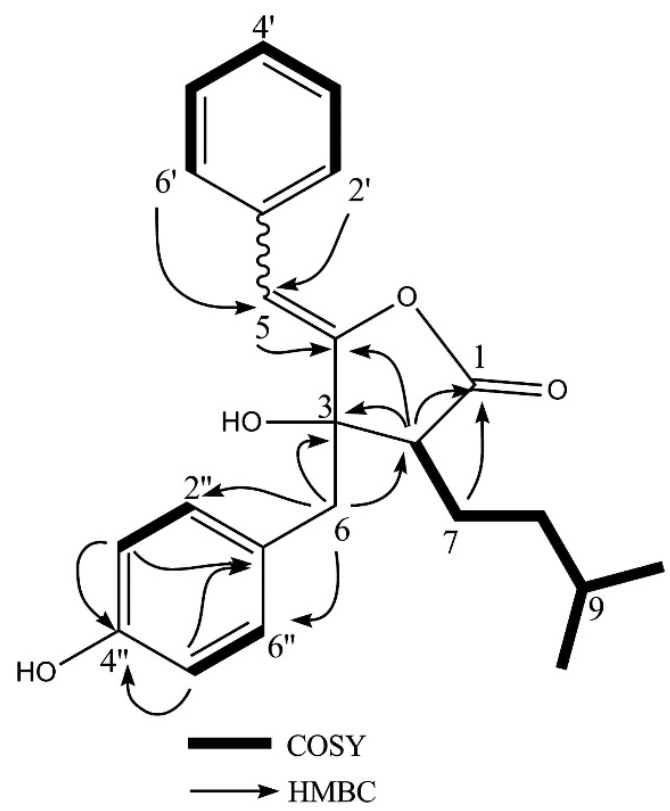

Figure 1 Key 2D NMR correlations $\left(500 \mathrm{MHz}\right.$, methanol- $\left.d_{4}\right)$ for angiolactone (1).

moiety (Figure 1). COSY correlations from the aromatic methines $\mathrm{H}-2^{\prime}$ to $\mathrm{H}-6^{\prime}$ extended by HMBCs to the olefinic methine $\mathrm{H}-5\left(\delta_{\mathrm{H}}\right.$ 5.25) led to the construction of a mono-substituted aromatic ring attached to an exocyclic double bond (Figure 1). Moreover, HMBCs from $\mathrm{H}-2\left(\delta_{\mathrm{H}} 2.83\right)$ to the ester carbonyl C-1 $\left(\delta_{\mathrm{C}} 175.1\right)$ and to an oxy quaternary carbon $\mathrm{C}-3\left(\delta_{\mathrm{C}} 80.8\right)$, and from $\mathrm{H}_{2}-6\left(\delta_{\mathrm{H}} 2.96,2.65\right)$ to $\mathrm{C}-2\left(\delta_{\mathrm{C}} 52.2\right), \mathrm{C}-3$, and the oxygenated sp ${ }^{2}$ carbon C-4 $\left(\delta_{\mathrm{C}} 153.2\right)$ and together with long-range correlations from $\mathrm{H}-5$ to $\mathrm{C}-3$ and C-4 corraborated the presence of a substituted furanone ring. The final substituent on the furanone ring by examination of the COSY spectra revealed an isolated spin system $\left(\mathrm{H}_{3}-11-\mathrm{H}-2\right)$ consistent with an isopentyl group (Figure 1). On the basis of these data, the planar 
Table 1 Physico-chemical properties of 1

\begin{tabular}{lc}
\hline & 1 \\
\hline Appearance HR-ESI-MS $(\mathrm{m} / \mathrm{z})$ & Yellow oil \\
Found & $389.1746[\mathrm{M}+\mathrm{Na}]^{+}$ \\
Calcd & $389.1729\left(\mathrm{C}_{23} \mathrm{H}_{26} \mathrm{O}_{4} \mathrm{Na}\right)$ \\
{$[\alpha]_{D}(\mathrm{MeOH}) \mathrm{c}(0.03)$} & $(+) 39^{\circ}$ \\
UV $\lambda_{\max } \mathrm{nm}(\log \varepsilon)(\mathrm{MeOH})$ & $260(4.55)$ \\
\hline
\end{tabular}

Table 2 NMR ( $500 \mathrm{MHz}$, methanol- $\left.d_{4}\right)$ data for angiolactone (1)

\begin{tabular}{llccc}
\hline Pos & $\delta_{H}$, mult $(\mathrm{J} \mathrm{in} \mathrm{Hz})$ & $\delta_{C^{a}}$ & COSY & HMBC \\
\hline 1 & & 175.1 & & \\
2 & $2.83, \mathrm{dd}(7.9,6.7)$ & 52.2 & 7 & $1,3,6,7,8$ \\
3 & & 80.8 & & \\
4 & & 153.2 & & \\
5 & $5.25, \mathrm{~s}$ & 105.8 & & $3,4,2^{\prime}, 6^{\prime}$ \\
$6 \mathrm{a}$ & $2.96, \mathrm{~d}(13.6)$ & 41.2 & & $2,3,4,1^{\prime \prime}, 2^{\prime \prime}, 6^{\prime \prime}$ \\
$6 \mathrm{~b}$ & $2.65, \mathrm{~d}(13.6)$ & & & $2,3,4,1^{\prime \prime}, 2^{\prime \prime}, 6^{\prime \prime}$ \\
7 & $1.82, \mathrm{~m}$ & 22.8 & $2,8 \mathrm{a} / \mathrm{b}$ & $1,2,3,8$ \\
$8 \mathrm{a}$ & $1.61, \mathrm{~m}$ & 37.8 & $7,8 \mathrm{~b}$ & \\
$8 \mathrm{~b}$ & $1.48, \mathrm{~m}$ & & $7,8 \mathrm{a}, 9$ & \\
9 & $1.65, \mathrm{~m}$ & 29.1 & $8 \mathrm{~b}, 10,11$ & \\
10 & $0.98 \mathrm{~b}, \mathrm{~d}(6.4)$ & 22.8 & 9 & $8,9,11$ \\
11 & $0.97 \mathrm{~b}, \mathrm{~d}(6.4)$ & 22.8 & 9 & $8,9,10$ \\
$1^{\prime}$ & & 135.2 & & \\
$2^{\prime}$ & $7.40, \mathrm{~d}(7.6)$ & 129.4 & $3^{\prime}$ & $5,4^{\prime}, 6^{\prime}$ \\
$3^{\prime}$ & $7.27, \mathrm{dd}(7.6,7.0)$ & 129.1 & $2^{\prime}, 4^{\prime}$ & $1^{\prime}, 5^{\prime}$ \\
$4^{\prime}$ & $7.17, \mathrm{dd}(7.2,7.0)$ & 127.6 & $3^{\prime}, 5^{\prime}$ & $2^{\prime}, 6^{\prime}$ \\
$5^{\prime}$ & $7.27, \mathrm{dd}(7.6,7.2)$ & 129.1 & $4^{\prime}, 6^{\prime}$ & $1^{\prime}, 3^{\prime}$ \\
$6^{\prime}$ & $7.40, \mathrm{~d}(7.6)$ & 129.4 & $5^{\prime}$ & $5,2^{\prime} 4^{\prime}$ \\
$1^{\prime \prime}$ & & 127.5 & & \\
$2^{\prime \prime}$ & $7.00, \mathrm{~d}(8.3)$ & 132.8 & $3^{\prime \prime}$ & $6,4^{\prime \prime}, 6^{\prime \prime}$ \\
$3^{\prime \prime}$ & $6.63, \mathrm{~d}(8.3)$ & 115.3 & $2^{\prime \prime}$ & $1^{\prime \prime}, 4^{\prime \prime}, 5^{\prime \prime}$ \\
$4^{\prime \prime}$ & & 157.4 & & \\
$5^{\prime \prime}$ & $6.63, \mathrm{~d}(8.3)$ & 115.3 & $6^{\prime \prime}$ & $1^{\prime \prime}, 3^{\prime \prime}, 4^{\prime \prime}$ \\
$6^{\prime \prime}$ & $7.00, \mathrm{~d}(8.3)$ & 132.8 & $5^{\prime \prime}$ & $6,2^{\prime \prime}, 4^{\prime \prime}$ \\
\hline
\end{tabular}

${ }^{\mathrm{a} 13 \mathrm{C}}$ NMR resonances obtained from $2 \mathrm{D} \mathrm{HSQC}$ and HMBC experiments.

boverlapping signals.

structure of angiolactone (1) was determined to be 5-benzylidene-4hydroxy-4-(4-hydroxybenzyl)-3-isopenty- $\gamma$-butyrolactone. Despite our efforts in experimenting with different media components to get a better production for $\mathbf{1}$, we were unsuccessful in ramping up production of $\mathbf{1}$ and as a result were not able to acquire enough material to address the stereochemistry and bioactivity of $\mathbf{1}$.

Butyrolactones are ubiquitously present in microbes and plants and they have been frequently associated with their role as quorum-sensing signaling molecules for activating antibiotic production in actinomycetes. $^{2}$ The diversity of butyrolactones in myxobacteria is however much lower with the known example being
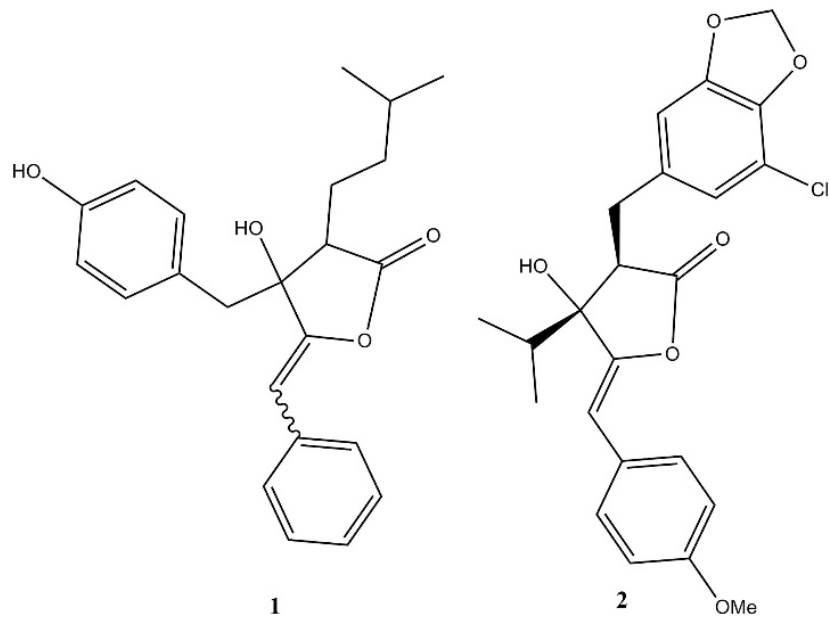

Figure 2 Structures of 1 and 2 .

the structurally unique leupyrrins. ${ }^{3}$ The closest known metabolite to 1 was cyanobacterin 2 , a chlorine-containing $\gamma$-lactone isolated from the freshwater cyanobacterium Scytonema hofmanni (Figure 2). ${ }^{4}$ In summary, we have successfully isolated and identified a new butyrolactone (1), a compound class, which is rare from myxobacterium.

\section{EXPERIMENTAL PROCEDURE}

NMR spectra were obtained on a Bruker Ascend $500 \mathrm{MHz}$ spectrometer equipped with a cryoprobe system (Bruker Biospin GmbH, Waldbronn, Germany), in the solvents indicated and referenced to residual ${ }^{1} \mathrm{H}$ signals in deuterated solvents. ESI-MS were acquired using an Agilent 1100 Series separations module equipped with an Agilent 1100 Series LC/MSD mass detector in both positive and negative ion modes under the following conditions: Zorbax $\mathrm{C}_{8}$ column, $150 \times 4.6 \mathrm{~mm}$, eluting with $0.4 \mathrm{ml} \mathrm{min}^{-1}$ $95 \% \mathrm{H}_{2} \mathrm{O} / \mathrm{MeCN}$ to $5 \% \mathrm{H}_{2} \mathrm{O} / \mathrm{MeCN}$ (with isocratic $0.01 \%$ trifluoroacetic acid) over $22 \mathrm{~min}$, then held for $5 \mathrm{~min}$. HRMS was carried out using an UltiMate 3000 rapid separation liquid chromatography system (Dionex RSLC, Crawford Scientific, Lanarkshire, Scotland, UK) coupled to an UHR-TOF mass spectrometer (Bruker Daltonik MaXis) operating in the positive ESI mode.

\section{ACKNOWLEDGEMENTS}

Research in R.M.'s laboratory was supported by grants from the BMBF and the DFG.

1 Weissman, K. J. \& Müller, R. Myxobacterial secondary metabolites: bioactivities and modes-of-action. Nat. Prod. Rep. 27, 1276-1295 (2010).

2 Du, Y.-L., Shen, X.-L., Yu, P., Bai, L.-Q. \& Li, Y.-Q. Gamma-butyrolactone regulatory system of Streptomyces chattanoogensis links nutrient utilization, metabolism and development. Appl. Environ. Microbiol. 77, 8415-8426 (2011).

3 Bode, H. G. et al. The Leupyyins: a structurally unique family of secondary metabolites from the myxobacterium Sorangium cellulosum. J. Nat. Prod. 66, 1203-1206 (2003).

4 Pignatello, J. J. et al. Structure of the antibiotic cyanobacterin, a chlorine-containing $\gamma$-lactone from the freshwater cyanobacterium Scytonema hofmanni. J. Org. Chem. 48, 4035-4038 (1983).

Supplementary Information accompanies the paper on The Journal of Antibiotics website (http://www.nature.com/ja) 